\title{
Assessment of Prevalence of Dental caries among smokers and smokeless tobacco users - A Descriptive Study
}

\author{
$\mathrm{Nidhi}^{1}$, S P Singh ${ }^{2}$ \\ ${ }^{1}$ Assisstant Professor, Dental Department, Jawaharlal Nehru Medical College and Hospital, Bhagalpur, Bihar, ${ }^{2}$ Professor and \\ HOD, Department of ENT and Dental, Jawaharlal Nehru Medical College and Hospital, Bhagalpur, Bihar, India
}

Corresponding author: Dr Nidhi, Assisstant Professor, Dental Department, JLNMCH, Bhagalpur, India

DOI: http://dx.doi.org/10.21276/ijcmsr.2019.4.1.2

How to cite this article: Nidhi, S P Singh. Assessment of prevalence of dental caries among smokers and smokeless tobacco users - a descriptive study. International Journal of Contemporary Medicine Surgery and Radiology. 2019;4(1):A4-A8.

\section{A B S T R A C T}

Introduction: Tobacco is the disease producing product due to the genus "Nicotiana" which is found in the leaves of plants. It is originally derived from species "Nicotiana tabacum". It has been reported from previous literature that usage of tobacco has various negative effects on oral health. Nicotine is one of the major constituents. Since, caries is a microbial disease and its prevalence is unknown among those who consume tobacco in Bihar. Hence, the aim of the present study was to assess the prevalence of dental caries among smokers and smokeless tobacco users.

Materials and methods: In this study, 256 individuals (110 females, 146 males) were included. Out of 256 individuals, 110 were females and 146 were males aged between 18 and 75 years were categorized into two groups. Group A had 126 individuals who were habitual smokers with a history of habit for a minimum of 6 months. Similarly, Group B had 130 individuals with a history of tobacco usage in smokeless form and had abused it since 6 months. DMFT (Decayed, Missing, and Filled Teeth Index-WHO modification 1987) was used to assess caries experience of study group.

Results: The study revealed a higher prevalence of dental caries among Group 2 which was of smokeless tobacco users than Group 1 which was smoking users only. In both the groups, prevalence of dental caries was more commonly seen in males than females.

Conclusion: The higher presence of caries in the Smokeless Tobacco user group might be due to the presence of sweeteners in tobacco-chewing agents. Caries prevalence was less among smokers probably to thiocyanate (anticariogenic) activity in their saliva.

Keywords: Smoking, Dental Caries, Smokeless Tobacco, Prevalence

\section{INTRODUCTION}

Globally, there is a growing burden of cigarette smoking and other tobacco use which has imposed imbalance for public health. Annually, approximately, 5 million people died due to the use of tobacco. In 2030, according to the latest trends, in low and middle income countries, it is suggested that this number will raise upto 10 million with $70 \%$ of deaths. There are various studies from high-income countries, and a growing number from low and middle income countries, which provided data that suggested increase in the rise of tobacco taxes, dissemination of information about health risks due to smoking, restrictions in public places about smoking and in work-places, comprehensive bans on advertising and promotion and increased access to cessation therapies were all found to be effective in decreasing tobacco use and its consequences. ${ }^{1,2}$

In India, cigarette smoking is the most common pattern of tobacco consumption. Many tobacco consumption patterns are used because many tobacco products are commercially available. According to the form of tobacco usage, many tobacco products are available, that is, raw, processed mixtures, and in the form of pyrolyzed products. The raw forms consists of the flakes of plain tobacco leaves mixed with lime, areca nut, and/or other condiments, which are sun cured or air cured. Mishri, bajjar, etc.,which are pyrolyzed forms, are used as dentifrices. In various parts of India, oral snuff is used. After the introduction of gutkha, the marketing and commercial production of ST has been up scaled.,

The harmful effects of smokeless tobacco use are perhaps not as well-known as those produced by smoking. Smokeless tobacco use has been known as aetiology of cancer. Various other effects of smokeless tobacco include leukoplakia, periodontal disease, and delayed wound healing along with dental caries. ${ }^{5}$

The relation between smoking and dental caries is a matter of various suggestions given by authors. It was recorded from the previous literature research and also a common belief that smoking actually helps to decrease dental caries. In a study by Schmidt, he supported this belief that increase in tobacco smoking was followed by a reduction in caries rate. The concentration of thiocyanate, a constituent of tobacco smoke and normal saliva with possible caries-inhibiting 
effect, was found to be increased in the saliva of smokers. So, there are chances that there might be less prevalence of dental caries among smokers. ${ }^{6,7}$

Increased susceptibility to caries on the other hand is found to be due to decreased buffering effect and possible lower $\mathrm{pH}$ of smoker's saliva and the higher number of Lactobacilli and Streptococcus mutans. Also, there was no significant difference in salivary flow rates between smokers and nonsmokers as reflected by the results. Till date, very few authors have found a correlation between elevated smoking level and dental caries. Such as, in 1952, Ludwick and Massler reported that those who smoked more than 15 cigarettes a day had significantly increased number of decayed, missing, and filled teeth. ${ }^{8,9}$

Numerous studies considered multiple variable factors which can contribute directly or indirectly to the increase in the incidence of dental caries in smokers such as age, tobacco habits other than smoking, oral hygiene habits, eating habits, drinking habits, preventive visits to dentist (dental recalls) and overall health standards. Because of these factors, it was difficult to conclude the association between single positive factors which can cause increase in caries incidence among smokers; therefore, further studies are required to establish the strength of relationship between smoking and dental caries. $^{10,11}$

Association between smoking and dental caries is well reported among older age groups. It was found that among middle-age (15) or young adults (25) results were inconsistent. Non-smokers documented with more frequent healthy oral health behaviour than did daily smokers. Studies showed that smokers not only had bad oral hygiene and less primitive outlook on health, but also had different eating habits, presumably consuming high amount of sugar containing products like soft drinks and snacks. Daily smoking was associated with increased use of sugar in tea or coffee, and with more frequent alcohol consumption. It is also seen that smokers have ineffective brushing habits than non-smokers. ${ }^{12,13}$

Furthermore, many tobacco additives has high amount of sugars. Such as, fruit juices, honey, molasses extracts, cones and maple syrup and caramel. The added sugars are usually reported to serve as flavour/casing and humectants. However, sugars also promote tobacco smoking, because they generate acids that neutralize the harsh taste and throat impact of tobacco smoke. Moreover, the sweet taste and the pleasant smell of caramelized sugar flavours are appreciated in particular by starting adolescent smokers. ${ }^{14}$

All the above findings can contribute to an increased prevalence of dental caries among smokers. However, a direct etiological relation between smoking and dental caries is still missing. The previous literature discussed both the increased and decreased prevalence of dental caries in tobacco users. However, the data is insufficient in the Indian context of Bihar city. ${ }^{15}$ Thus, the aim of the present study was to assess the prevalence of caries in smokers and Smokeless Tobacco users.

\section{MATERIAL AND METHODS}

The present observational study was designed to estimate the prevalence of caries in the patients who have been using tobacco in either smoking or smokeless forms. The study was conducted in the Jawaharlal Medical College and Hospital, Bhagalpur for a period of four months. The institutional ethical review board approved the study protocol, and informed consent was obtained from the patients. A simple random sampling was performed during recruitment. All data pertaining to the habit duration, type, frequency, and form were recorded in a preformed proforma. Conversely, patients who were clinically diagnosed with dental fluorosis were excluded from the study. Out of 256 individuals, 110 were females and 146 were males aged between 18 and 75 years were categorized into two groups. Group A had 126 individuals who were habitual smokers with a history of habit for a minimum of 6 months. Similarly, Group B had 130 individuals with a history of tobacco usage in smokeless form and had abused it since 6 months. A thorough clinical examination was conducted along with dental caries scores using Black's classification. The criteria to diagnose decayed tooth used was: catch with explorer, discontinuity of enamel surface, definite cavitation and soft base. Patients were asked to rinse mouth thoroughly before examination, then the teeth were dried with cotton swab and dental caries were recorded. DMFT index was used where D represents number of decayed teeth, $\mathrm{M}$ is the number of missing teeth and $\mathrm{F}$ is the number of filled teeth and $T$ is used to represent tooth.

\section{STATISTICAL ANALYSIS}

The results obtained were entered into Microsoft excel sheet and analysed using SPSS version 21. Descriptive statistics were used including percentage, mean and standard deviation.

\section{RESULTS}

In the present study, Table- 1 shows the distribution of patients based on gender and habit. It was found that out of

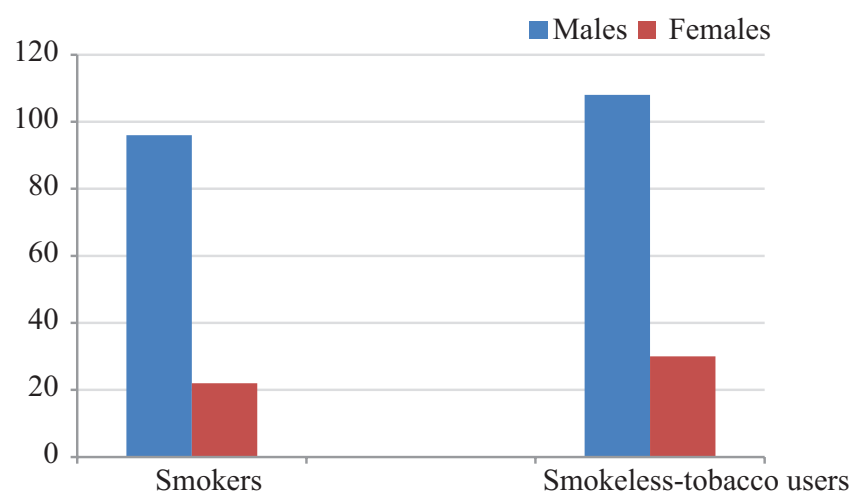

Graph-1: Shows the distribution of smoking users and smokeless-tobacco users based on gender

\begin{tabular}{|l|c|}
\hline Gender & Frequency N (\%) \\
\hline Males & 146 \\
\hline Females & 110 \\
\hline Habit & 118 \\
\hline ST-chewers & 138 \\
\hline Non ST-chewers & \multicolumn{2}{|c|}{ and habit } \\
\hline Table-1: Shows the distribution of patients based on gender \\
\hline
\end{tabular}




\begin{tabular}{|l|c|c|c|c|c|c|}
\hline Parameters & \multicolumn{3}{|c|}{ Case-Smoke } & \multicolumn{3}{|c|}{ Case-Smokeless Tobacco } \\
\hline Type of smoking & Mean & SD & N & Mean & SD & N \\
\hline 0 & 2.16 & 2.48 & 70 & 3.16 & 3.45 & 45 \\
\hline 1 & 1.59 & 2.94 & 48 & 2.40 & 1.96 & 56 \\
\hline 2 & 0 & 0 & 0 & 2.16 & 2.42 & 18 \\
\hline 3 & 0 & 0 & 0 & 3.04 & 3.68 & 14 \\
\hline 4 & 0 & 0 & 0 & 6.48 & 0 & 5 \\
\hline Frequency & Mean & SD & $\mathbf{N}$ & Mean & SD & N \\
\hline $1-5$ & 2.12 & 2.24 & 94 & 2.62 & 3.16 & 84 \\
\hline $6-10$ & 2.96 & 3.62 & 16 & 2.94 & 3.62 & 32 \\
\hline$>10$ & 2.98 & 3.94 & 8 & 3.18 & 3.04 & 22 \\
\hline Duration in Years & Mean & SD & $\mathbf{N}$ & Mean & SD & N \\
\hline$<5$ & 2.32 & 2.48 & 48 & 1.48 & 2.34 & 68 \\
\hline $6-10$ & 2.94 & 1.41 & 26 & 2.78 & 2.14 & 24 \\
\hline $11-15$ & 1.82 & 1.26 & 19 & 1.58 & 1.08 & 13 \\
\hline $16-20$ & 2.42 & 1.19 & 6 & 2.46 & 1.32 & 9 \\
\hline $21-25$ & 2.84 & 1.56 & 8 & 1.18 & 1.41 & 8 \\
\hline $25-30$ & 1.94 & 2.64 & 5 & 1.32 & 1.09 & 6 \\
\hline$<30$ & 1.16 & 2.41 & 6 & 1.21 & 1.62 & 10 \\
\hline
\end{tabular}

Table-2: Shows the distribution between the smoking group and the group using smokeless tobacco based upon type, frequency and duration (Type of tobacco smoking: $0=$ beedi and $1=$ cigarette. Type of smokeless tobacco: $0=$ gutka, $1=$ zarda, $2=$ khaini, $3=$ tambaku, and $4=$ snuff).

\begin{tabular}{|c|c|c|c|c|c|}
\hline \multirow[b]{2}{*}{ Group 1} & \multirow[b]{2}{*}{ Age } & \multicolumn{2}{|c|}{ Caries free } & \multicolumn{2}{|c|}{ With Caries } \\
\hline & & $\mathbf{N}$ & $\%$ & $\mathbf{N}$ & $\%$ \\
\hline & $<25$ & 4 & 3.17 & 26 & 20.63 \\
\hline & $26-35$ & 12 & 9.52 & 32 & 25.39 \\
\hline & $36-45$ & 2 & 1.58 & 16 & 12.69 \\
\hline & $46-55$ & 8 & 6.34 & 11 & 8.73 \\
\hline & $56-65$ & 3 & 2.38 & 4 & 3.17 \\
\hline & $>65$ & 1 & 0.79 & 2 & 1.58 \\
\hline \multicolumn{6}{|l|}{ Gender } \\
\hline & Males & 50 & 34.24 & 96 & 65.75 \\
\hline & Females & 64 & 58.18 & 46 & 41.81 \\
\hline
\end{tabular}

\begin{tabular}{|c|c|c|c|c|c|}
\hline \multirow[b]{2}{*}{ Group 2} & \multirow[b]{2}{*}{ Age } & \multicolumn{2}{|c|}{ Caries free } & \multicolumn{2}{|c|}{ With Caries } \\
\hline & & $\mathbf{N}$ & $\%$ & $\mathbf{N}$ & $\%$ \\
\hline & $<25$ & 2 & 1.53 & 54 & 41.5 \\
\hline & $26-35$ & 4 & 3.07 & 36 & 27.6 \\
\hline & $36-45$ & 5 & 3.84 & 14 & 10.76 \\
\hline & $46-55$ & 6 & 4.61 & 12 & 9.23 \\
\hline & $56-65$ & 2 & 1.53 & 8 & 6.15 \\
\hline & $>65$ & 2 & 1.53 & 6 & 4.61 \\
\hline \multicolumn{6}{|l|}{ Gender } \\
\hline & Males & 42 & 28.76 & 104 & 71.2 \\
\hline & Females & 58 & 52.72 & 52 & 47.27 \\
\hline
\end{tabular}

256 patients, 146 were found to be males and 110 were found to be females. Out of which smoking users were found to be 118 and smoke-less tobacco users were found to be 138.

Table-2 shows the correlation between the smoking group and the group using smokeless tobacco based upon type, frequency and duration among the study subjects. It was revealed that among smokers, bidi was more commonly used than cigarettes and in smokeless tobacco users tambhaku was used by majority of the study subjects followed by gutkha, khaini and zarda. Among smokers, majority of the subjects smoked 1-5 times in a day followed by 6-10 times and very few used more than 10 times in a day. Among smokeless tobacco users, majority of the subjects used 1-5 times in a day followed by more than 10 times in a day. The duration was found to be more than 6-10 years and 21-25 years followed by less than 5 years and $25-30$ years. 
Table- 3 shows that among smokers, most common age group affected with caries was found to be $26-35$ years followed by less than 25 years. The males $(65.75 \%)$ were more commonly affected with dental caries than females (41.81\%). Table no. 4 showed that among smokeless tobacco users, the most common age group affected with dental caries was found to be less than 25 years followed by $26-35$ years. The males (71.2\%) were most commonly affected than females (47.27\%). Thus, among both the groups dental caries was more prevalent among smokeless tobacco users than smoking alone.

Graph-1 shows that smokeless tobacco was most commonly used by males than smoking and among females smokeless tobacco was most commonly used than smoking. Males were having higher prevalence of using tobacco than females.

\section{DISCUSSION}

India is the second largest consumer of tobacco globally. The tobacco problem in India is peculiar, with consumption of variety of smokeless and smoking forms. The estimates of the Global Adult Tobacco Survey (GATS) conducted among persons 15 years of age or older during 2009-10 indicated that $34.6 \%$ of the adults were tobacco users. Majority of them were smokeless tobacco consumers. ${ }^{16}$

A study was conducted by Zitterbart et al in 1990 which reported that smokers had significantly higher decayed, missing, and filled teeth (DMFT) score, untreated decayed surfaces, and missing surfaces, which confirmed an association between smoking and the prevalence of dental caries in adult males. He further correlated that the more the cigarettes were smoked per day, the more the missing teeth were noted in a smoker's mouth. In the present study, males had a more prevalence of dental caries than females. ${ }^{10}$

Earlier reports in literature indicated that dental caries were reduced in individuals having a smoking habit which suggested that smoking in reality reduces dental caries which is due to the concentration of thiocyanate, a constituent of tobacco smoke, has possible caries-inhibiting effect. It was found to be higher in smoker's saliva, thus depicted that smoking had inhibitory effect on smoking. ${ }^{17}$

On the other hand, few studies also stated that increased susceptibility to dental caries might be due to possible lower $\mathrm{pH}$ levels, a decreased buffering capacity of smoker's saliva, and the higher number of lactobacilli and Streptococcus mutans. Results from few studies reported that salivary flow rates between smokers and non-smokers showed no significant differences. As the smoking frequency increases, dental caries was also found to be increased which is similar to the findings of the present study. ${ }^{18}$

In 2007, Dietrich et al. studied tobacco use and the incidence of tooth loss among US male healthcare professionals. They found that the data on the dose-dependent effect of smoking and smoking cessation on tooth loss were scarce. They hypothesized that smoking had both dose- and timedependent effects on tooth loss incidence. ${ }^{19}$

The previous research on Smokeless Tobacco use with either increasing or decreasing dental caries incidence is deficient. More dental caries were reported in individuals who chewed tobacco than nonusers. Similar findings were reflected from our study results. Data from the multipurpose health survey in USA from 1988 to 1994 which was the $3^{\text {rd }}$ National Health and Nutrition Examination Survey was used to examine the relationship between chewing tobacco and the other forms of tobacco use and decayed or filled coronal or root surface caries. The findings of this study showed that tobacco chewers had a slightly higher mean for decayed and filled coronal surfaces than individuals using the other forms of tobacco. Also, the mean number of decayed and filled root surface for those who used chewing tobacco was four times higher than non-users. ${ }^{20}$

Studies have revealed that natural form of tobacco contains sugars in it. In natural tobacco, sugar can be present in a level up to $20 \%$ by weight (wt). In a study done by Hellqvist et al. reported that the nicotine-containing tobacco products contained traces of glucose, fructose and sucrose (0.5-1\%) and starch (approximately 1.5\%). In addition, various sugars and sweeteners are added intentionally during tobacco manufacturing process to mask the bitter taste of it. This range of sugar and sweetener can vary from $4 \% \mathrm{wt}$ to $13 \%$ wt. Along with sweeteners; tobacco products have few additives which contain high amount of sugars, for example, fruit juices, honey, molasses extracts, cones and maple syrup and caramel. These agents can also be considered as one of the contributing factors towards increased dental caries incidence among Smoke-less Tobacco chewers. ${ }^{21}$

The limitations of the study were that there could have been clinical selection bias in the diagnosis of dental caries. Interobserver variability was not assessed, and the sample selection from a single centre may have led to variations in the study results, which might not reflect the actual prevalence of disease in the population. Therefore, further research is required with larger sample size in future to overcome these flaws.

\section{CONCLUSION}

This study demonstrated that the Smokeless-tobacco users are at a higher risk of experiencing dental caries when compared to smoking users.

\section{REFERENCES}

1. Jha P, Chaloupka FJ, Corrao M, Jacob B. Reducing the burden of smoking world-wide: effectiveness of interventions and their coverage. Drug Alcohol Rev. 2006; 25:597-609.

2. Banoczy J, Squier C. Smoking and disease. Eur J Dent Educ. 2004; 8 Suppl 4:7-10.

3. Winn DM. Tobacco use and oral disease. J Dent Educ. 2001; 65:306-12.

4. Soni PR, DK. Prevalence and pattern of tobacco consumption in India. Int Res J Social Sci 2012; 1:8.

5. Mayuri Borse, Priya Nagar, Jessy P, Pai Tanvi. Dental Caries in Primary and Permanent Molars in 7-8-Year Old School Children Evaluated with Caries Assessment Spectrum and Treatment (CAST) Index from Bangalore North. International Journal of Contemporary Medical Research. 2016;3:2275-2278.

6. Schmidt HJ. Tobacco smoke and the teeth. Stoma (Heidelb). 1951; 4:111-25.

7. Kassirer B. Smoking as a risk factor for gingival problems, periodontal problems and caries. Univ Tor 
Dent J 1994; 7:6-10.

8. Saud Moflih Al-Otaibi, Hazem Rizk, Mohamed Abdulcader Riyaz. Prevalence of Dental Caries, Salivary Streptococcus Mutans, Lactobacilli Count, $\mathrm{pH}$ level and Buffering Capacity among children with Down's Syndrome in Al-Qassim Region, KSA. International Journal of Contemporary Medical Research. 2019;3:2793-2797.

9. Ludwick W, Massler M. Relation of dental caries experience and gingivitis to cigarette smoking in males 17 to 21 years old (at the Great Lakes Naval Training Center). J Dent Res. 1952; 31:319-22.

10. Zitterbart PM, Marlin DC, Christen AG. Dental and oral effects observed in a long-term tobacco chewer: Case report. J Indiana Dent Assoc 1983; 62:2.

11. Going RE, Hsu SC, Pollack RL, Haugh LD. Sugar and fluoride content of various forms of tobacco. J Am Dent Assoc 1980; 100:27-33.

12. Locker D. Smoking and oral health in older adults. Can J Public Health. 1992; 83:429-32.

13. Jette AM, Feldman HA, Tennstedt SL. Tobacco use: a modifiable risk factor for dental disease among the elderly. Am J Public Health. 1993; 83:1271-6.

14. Falkler WA Jr, Zimmerman ML, Martin SA, Hall ER. The effect of smokeless-tobacco extracts on the growth of oral bacteria of the genus Streptococcus. Arch Oral Biol. 1987; 32:221-3.

15. Taybos G. Oral changes associated with tobacco use. Am J Med Sci. 2003; 326:179-82.

16. Global Adult Tobacco Survey (GATS) India: 20092010. Available from http://www.searo.who.int/ LinkFiles/Regional_Tobacco_Surveillance_System_ GATS_India.pdf. Published by IIPS, Mumbai and funded by the Ministry of Health and Family Welfare, GOI 2010.

17. Tasneem S. Ain, Saima Sultan, Owais Gowhar, Ravishankar TL, Sumit Kumar. Prevalence of Dental Caries among 12 Year Old School Children in Kashmir, India - A Cross-Sectional Study. International Journal of Contemporary Medical Research 2016; 3:2156-2159.

18. Huang R, Li M, Gregory RL. Effect of nicotine on growth and metabolism of Streptococcus mutans. European Journal of Oral Sciences. 2012; 120: 319-325.

19. Dietrich T, Maserejian NN, Joshipura KJ, Krall EA, Garcia RI. Tobacco use and incidence of tooth loss among US male health professionals. J Dent Res 2007; 86:373-7.

20. Tomar SL, Winn DM. Chewing tobacco use and dental caries among U.S. men. J Am Dent Assoc. 1999 Nov; 130:1601-10. Erratum in: J Am Dent Assoc. 1999; 130:1700.

21. Hellqvist L, Rolandsson M, Hugoson A, Lingström P, Birkhed D. Dental caries and associated factors in a group of Swedish snuff users. Swedish Dental Journal. 2015; 39: 47-54.

Source of Support: Nil; Conflict of Interest: None

Submitted: 09-12-2018; Accepted: 25-12-2019; Published online: 28-01-2019 